\title{
An unusual case of prostate tuberculosis: a case report
}

This article was published in the following Dove Press journal:

International Medical Case Reports Journal

2 May 2015

Number of times this article has been viewed

\author{
Ahmad Jasem Abdulsalam' \\ Mohammad Adel \\ Abdulsalam ${ }^{2}$ \\ 'Faculty of Medicine, Health Science \\ Center, Jabriya, Kuwait; ${ }^{2}$ Mubarak Al \\ Kabeer Hospital, Jabriya, Kuwait
}

Introduction: Tuberculosis of the prostate is a rare complication of miliary tuberculosis. Case presentation: We report a 32-year-old Iranian male diagnosed with a case of miliary tuberculosis affecting the prostate. The patient was admitted to the hospital with convulsions. Computerized tomography increased the clinical suspicion of miliary tuberculosis extending to the prostate where a trans-rectal urethral biopsy was obtained. The biopsy revealed multiple necrotizing granulomata suggestive of tuberculosis.

Conclusion: A strong clinical suspicion and availability of sophisticated tests with confirmation by biopsy, polymerase chain reaction, and culture are needed in order to avoid misdiagnosis of complicated miliary tuberculosis cases.

Keywords: miliary, tuberculosis, prostate, disseminated, complication

\section{Introduction}

Miliary tuberculosis is a rare form of a tuberculosis infection that results from massive lymphohematogenous dissemination of the mycobacterium tuberculosis bacilli. ${ }^{1}$ This form of infection, which accounts for $2.8 \%$ of all tuberculosis infections, usually involves the extrapulmonary organs. ${ }^{2}$ From extrapulmonary tuberculosis only $22 \%$ affects the genitourinary system, while tuberculosis of the prostate gland is seen in only $2.7 \%$ of genitourinary tuberculosis. ${ }^{3,4}$ Due to the rare involvement of the prostate, very scarce literature of the subject, and non-specific symptoms, the clinical suspicion of prostate tuberculosis is difficult. Here we report a case of a young, previously healthy, immunocompetent patient with miliary tuberculosis involving the prostate.

\section{Case report}

We present a case of a 32-year-old immunocompetent Iranian male who presented to the emergency room with a generalized tonic-clonic seizure lasting for 3 minutes. He denied any history of trauma, fever, or previous seizures. Furthermore, he did not have any genitourinary symptoms, including dysuria, hematuria, or penile discharge. A computerized tomography (CT) scan of the head failed to show any acute central nervous system insult.

After that, the patient was admitted to the hospital. Prior to this admission, he gave history of an admission 12 months ago to a hospital outside the country, where he complained of fatigue, weight loss, and fever. Reports from the hospital showed that he also had chronic moderate ascites and a left pleural effusion. However, several laboratory and imaging tests were done and it was concluded that there was no evidence of infectious disease, chronic liver disease, or malignancy. It was recommended
Correspondence: Ahmad Jasem Abdulsalam

Faculty of Medicine, Health Science Center, PO Box 24923, Safat I3110 Jabriya, Kuwait

Tel +9659792 3190

Emaila7medo@gmail.com

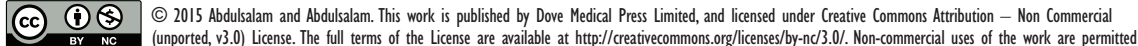
without any further permission from Dove Medical Press Limited, provided the work is properly attributed. Permissions beyond the scope of the License are administered by Dove Medical Press Limited. Information on how to request permission may be found at: http://www.dovepress.com/permissions.php 
that he may need more investigations or a laparoscopy with peritoneal tissue biopsy, which was not done.

Upon the latest admission, the respiratory rate was 12 breaths per minute, the body temperature was $36.9^{\circ} \mathrm{C}$, and the blood pressure was $112 / 70 \mathrm{mmHg}$. The patient had mild tachycardia of 109 beats per minute. Physical examination was unremarkable including the respiratory system examination. Digital rectal examination was not performed since the patient did not have any genitourinary or gastrointestinal symptoms. During this hospitalization, the patient received anti-epileptic treatments and multiple investigations were done. The laboratory investigations, urine routine and microscopy, cultures, virology screen, including human immunodeficiency virus, as well as the autoimmune markers did not show any significant issues. Also, three sets of sputum acid-fast bacilli smears were done, which were all negative. Further invasive tests were performed including endoscopy and colonoscopy which were unremarkable. A lumber puncture was also performed with a normal initial pressure, $0 \mathrm{~mm}^{3}$ cell count, glucose of $4.1 \mathrm{~mm}$ per liters, and protein of $764 \mathrm{mg}$ per liter. At the same time the serum glucose was $6 \mathrm{mmol}$ per liter. A magnetic resonance image of the brain was done concluding multifocal enhancing foci suggestive of an infective process (Figure 1).

Due to his previous history, CT-chest, abdomen, and pelvis were also done. The chest-CT was unremarkable. The abdominal CT showed mild peritoneal ascites with evidence of

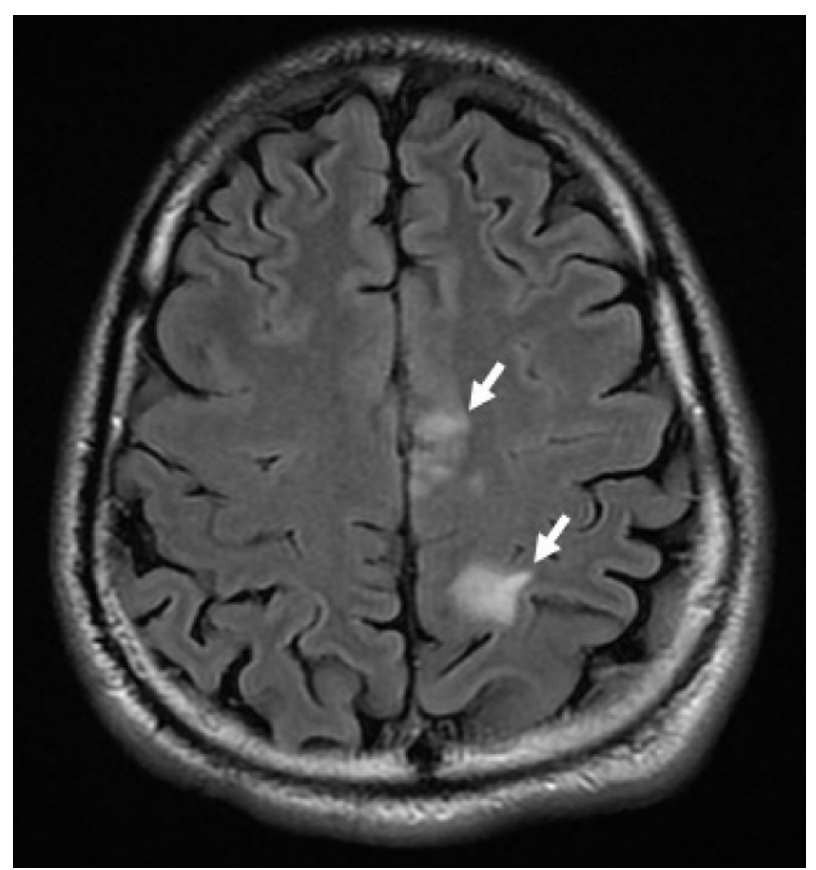

Figure I Multifocal T2 magnetic resonance image showing high signal intensity noted in parasagittal left frontoparietal region; there is intense punctuate enhancement post-gadolinium contrast (white arrows). mild splenomegaly. The ascetic fluid taken was translucent and yellow in color and the serum-ascites albumin gradient 5 gram per liter ( 0.5 gram per deciliter). Furthermore, the analysis was negative for Ziehl-Neelsen, gram stain, and culture.

The pelvis CT also showed an enlargement of the prostate and a right prostate lesion extending to the seminal vesicles (faint ring enhancing lesion measuring $3 \times 2.7 \times 3 \mathrm{~cm}$ ) (Figure 2).

The case was discussed with the patient and he agreed to start anti-tuberculosis treatment and to have a trans-rectal biopsy of the prostate. The biopsy showed multiple slides of necrotizing granulomata suggestive of tuberculosis (Figure 3). Ziehl-Neelsen stain was also performed, and the diagnosis of miliary tuberculosis was confirmed (Figure 4).

He was started on anti-tuberculosis therapy with isoniazid, rifampicin, ethambutol, pyrazinamide, and pyridoxine for 12 months. At follow-up the prostate biopsy tubercle bacilli culture result came back positive. The patient was asymptomatic with a normal physical examination and laboratory tests with no drug side effects.

\section{Discussion}

Miliary tuberculosis is the widespread dissemination of mycobacterium tuberculosis by means of lymphohematogenous spread. This complication is seen in $1 \%-3 \%$ of all tuberculosis cases. ${ }^{5}$ Although most cases of miliary tuberculosis are treatable, the mortality rate among young adults with miliary tuberculosis remains $15 \%-20 \%$ and for adults $25 \%-30 \% .^{2}$ One of the main causes for these high mortality rates includes late detection of disease caused by non-specific symptoms. These symptoms may be implicated in numerous disorders, thus delaying diagnosis.

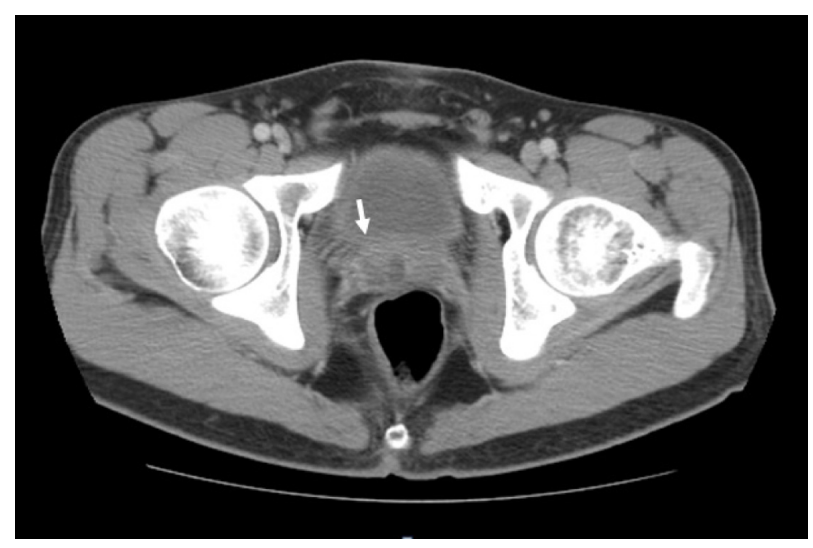

Figure 2 MDCT Helical axial cut of the pelvis showing the prostate is enlarged with a faint ring enhancing lesion measuring $3 \times 2.7 \times 3 \mathrm{~cm}$ (white arrow).

Note: The lesion takes up most of the right side of the prostate, extending to the right seminal vesicles.

Abbreviation: MDCT, multiple detector computed tomography. 


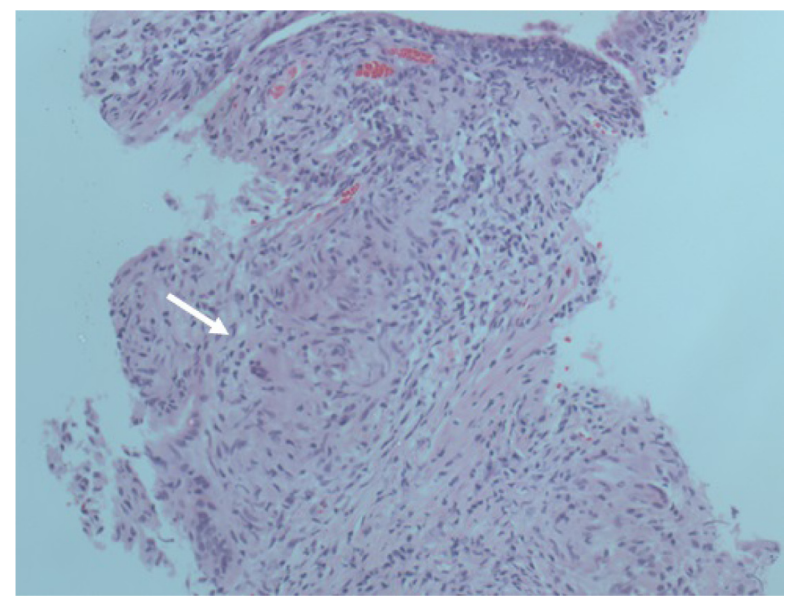

Figure 3 Light microscopy examination of the needle core prostatic biopsy showing multiple necrotizing granulomata with giant cells (white arrow), high suspicion of infective etiology; in particular mycobacterium bacteria.

Tuberculosis of the prostate is rare and the literature is scarce. Most often, the cases are under-reported, and easily missed. Patients with prostatic tuberculosis usually present with non-specific symptoms except in rare cases. These rare cases present with irritative voiding symptoms, terminal dysuria or hemospermia. ${ }^{6}$ However this was not the case in our patient. The patient was asymptomatic and like most cases in the literature, tuberculosis of the prostate was diagnosed incidentally. As in our case, tuberculosis of the prostate is mainly diagnosed by pathologists where a trans-rectal ultrasound guided biopsy of the prostate is the mainstay of the diagnosis. ${ }^{7}$ As Wang and Chang have demonstrated, it was the clinical usefulness of the contrast enhanced $\mathrm{CT}$ for the diagnosis of tuberculosis of the prostate in which low density multiple and bilateral lesions with irregular borders are seen that prompted us to further investigate the prostate. ${ }^{8}$

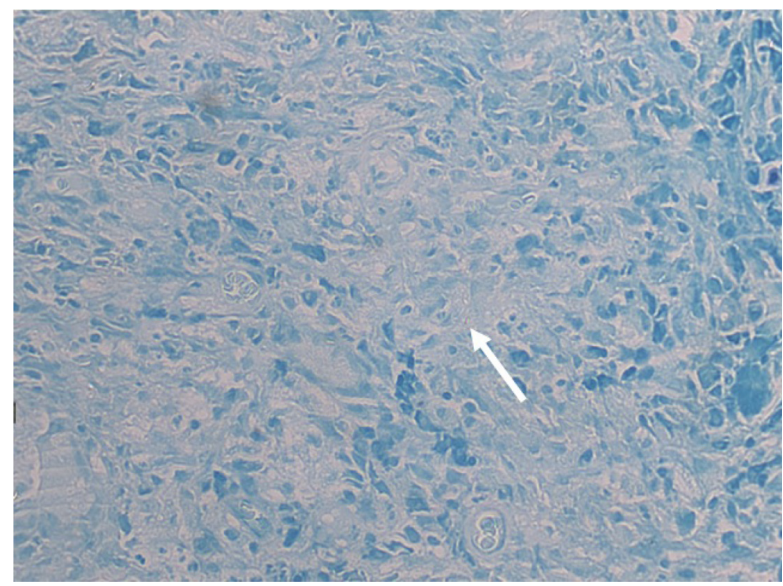

Figure 4 Ziehl-Neelsen histochemical stain prepared on the paraffin block tissue showed positive staining of rare occasional acid-fast bacilli (white arrow) within the epithelioid granulomata and necrotic debris, confirming mycobacterium bacteria.
Once the disease is diagnosed, the patient should receive a full course of anti-tubercular therapy.

\section{Conclusion}

The presentation of miliary tuberculosis infection is highly variable. Often, the presentation can be non-specific and misleading, as in our case. A strong clinical suspicion and availability of sophisticated tests with confirmation by biopsy, polymerase chain reaction, and culture are needed in order to avoid misdiagnosis of complicated miliary tuberculosis cases.

\section{Acknowledgments}

Written informed consent was obtained from the patient for publication of this case report and accompanying images. We acknowledge Senior Dr Mohammad Jasem Al Kandari and Dr Smiley Anne George in the Department of Pathology in Mubarak Al Kabeer Hospital, Kuwait for their insightful contributions and preparing the histopathology slides.

\section{Authors' contributions}

AJA and MAA both contributed equally by examining the patient, following up the patient, writing the manuscript, and reviewing the literature. Both authors read and approved the final manuscript.

\section{Disclosure}

The authors declare that they have no competing interests.

\section{References}

1. Sharma SK, Mohan A, Sharma A, Mitra DK. Miliary tuberculosis: new insights into an old disease. Lancet Infect Dis. 2005;5(7):415-430.

2. Lessnau KD, de Luise C. Miliary Tuberculosis. Medscape; 2015. Available from: http://emedicine.medscape.com/article/221777-overview. Accessed March 26, 2015.

3. Lessnau KD, Bylund JR, Deters LA, et al. Tuberculosis of the Genitourinary System Overview of GUTB. Medscape; 2015. Available from: http://emedicine.medscape.com/article/450651-overview\#aw2aab6b4 Accessed March 26, 2015.

4. Tuberculosis (TB). Atlanta: Centers for Disease Control and Prevention; 2015. Available from http://www.cdc.gov/tb/. Accessed March 26, 2015.

5. No authors listed. American Thoracic Society, US Centers for Disease Control and Prevention. Diagnostic Standards and Classification of Tuberculosis in Adults and Children. Am J Respir Crit Care Med. 2000; 161(4 Pt 1):1376-1395.

6. Lattimer JK, Weechsler M. Genito-urinary tuberculosis. In: Harrison JH, et al, editors. Campbell's Urology. 4th ed. Philadelphia: Saunders; 1978:1.

7. Chandra S, Gaur, DS, Chandra H, Vijjan V, Pathak VP. Tuberculosis of the prostate: report a case with unusual presentation. Infectious Diseases in Clinical Practice. 2009;17(6):399-400.

8. Wang JH, Chang T. Tuberculosis of the prostate: CT appearance. J Comput Assist Tomogr. 1991;15(2):269-270. 


\section{Publish your work in this journal}

The International Medical Case Reports Journal is an international, peer-reviewed open-access journal publishing original case reports from all medical specialties. Previously unpublished medical posters are also accepted relating to any area of clinical or preclinical science. Submissions should not normally exceed 2,000 words or

4 published pages including figures, diagrams and references. The manuscript management system is completely online and includes a very quick and fair peer-review system, which is all easy to use. Visit $\mathrm{http}: / /$ www.dovepress.com/testimonials.php to read real quotes from published authors.

Submit your manuscript here: http://www.dovepress.com/international-medical-case-reports-journal-journal 